\title{
Death \& Life: A Study on Pakistani Youth
}

\begin{abstract}
The aim of the present study was to explore the relation between Death Attitudes and Meaning in Life. Besides this exploratory approach, it was also hypothesized that 'Search for Meaning' would be significantly greater than 'Presence of Meaning' in youth population. For this purpose, 60 males and 60 female students were conveniently approached in University of Karachi to participate in the study. Two questionnaires were administered; Death Attitudes Profile - Revised (subscales; fear of death, death avoidance, neutral acceptance, approach acceptance and escape acceptance) and Meaning in Life (subscales; search for meaning and presence of meaning). Results revealed gender difference in two death attitudes. Hypothesis regarding search for meaning being greater than presence of meaning was proved. Exploratory analysis of death attitudes and meaning in life showed complex relation.
\end{abstract}

\author{
Sarwat Amin Rattani, Dr. Farah lqbal \\ University of Karachi \\ Sarwat.rattani@live.com \\ University of Karachi \\ iqbfarah@yahoo.com
}

\section{Indexing terms/Keywords}

death attitudes, meaning in life, youth, existential psychology, positive psychology, DAP-R

\section{Academic Discipline And Sub-Disciplines}

Psychology - Positive Psychology and Existential Psychology

\section{TYPE (METHOD/APPROACH)}

\author{
Correlational Study, Survey Method
}

\section{INTRODUCTION}

"Here is a small fact - you are going to die." - Markus Zusak, The Book Thief (2005)

Death indeed is a fact, an undeniable and unstoppable reality. But how many of us humans accept this ultimate change that life brings? The quote above is enough to transfix and cause great anxiety in the majority. Because death is viewed as macabre and more of a taboo by masses even today.

It was Herman Fiefel who initially broke this wall of taboo in scientific community. By his great efforts and long standing commitment to the subject, death and dying became a topic of research by 1950s. His books and articles dispelled many myths held by the scientific community on this topic ('Feifel, Herman', 2016). Fiefel's efforts resulted in other researchers following his path and thus, literature on death and dying accumulated. The five main areas that branched from his researches were; death attitudes in the elderly, the relationship of death concerns to physical illness, death anxiety of medical and non-medical caregivers, the relationship between fear of death and psychopathology, and association between religiosity and apprehension of death (Neimeyer, Wittkowski, \& Moser, 2004). Elderly studies showed that death anxiety decreased from middle age to older age. Health status though gives mixed results generally. However, one study showed that disease did not change death attitudes, rather the patients' current attitude had been shaped by previous stages of their sickness (Nozari \& Dousti, 2013). Research between professional caregivers and non-professional caregivers showed that individuals who had higher death anxiety held more negative towards elderly and face greater difficulty in disclosing terminal diagnosis. In the field on pathology, it was seen that greater neuroticism was accompanied by death anxiety and higher suicide risk was positively related to death concern. As for religious studies, higher religiosity was linked with lower level of death anxiety. Further research has shown a negative correlation between intrinsic religiosity and fear of death (Lobb, 2009).

A great deal of literature as we see has been dedicated to the study of death anxiety and fear of death. Langner (2002) in his book Choices for living: coping with Fear of dying cites seven main death attitudes given by Garden Murphy, that is; (1) Death is the end (no panic, no fear, acceptance), (2) Fear of losing consciousness (loss of control or mastery), (3) Fear of loneliness (separation from loved ones), (4) Fear of the unknown, (5) Fear of punishment (hellfire, mutilation, disintegration), (6) Fear of what might happen to loved ones left behind, especially dependents and (7) Fear of failure (unfulfilled lives, tasks left undone, regrets).

Attitudes given by Murphy include six fear of death concerns while one attitude aligns with acceptance of death. Like most of the literature, fear of death or death anxiety remains the foremost focus here. Why positive outlook towards death had not been taken while examining these negative attitudes? Why were they not researched simultaneously? This concern was brought in focus after the insights presented by Viktor Frankl. Frankl was a holocaust survivor. After losing his family, suffering anguish and getting tortured in concentration camp, he derived a theory belonging to Existential Approach toward psychology, called Logotherapy. His focus was on growth, wellbeing, self-transcendence and life's meaning. He believed meaning could be derived from greatest of the suffering and meaning seeking (the will to meaning) is a spiritual human motivation towards self-transcendence (Wong, 2014). In his book, Man's Search for Meaning he quotes; "Long ago we had passed the stage of asking what was the meaning of life, a naïve query which understands life as the attaining of 
some aim through the active creation of something of value. For us, the meaning of life embraced the wider cycles of life and death, of suffering and of dying." (Frankl, 1985). Thus, his theory gave a fresh perspective to the concept of suffering, death and dying.

One qualitative study examined death attitudes widely shown in mass media. Analysis revealed that many popular movies portray death unrealistically which promotes death denial, avoidance of death concerns, and repression of emotion in masses. But, at the same times concept of death acceptance was also perpetuated. Movies showed characters who rise above their disease, diagnoses or suffering and face death head on by living fully and evoking inner transformation, example movies Ikiru and Cast Away (Niemiec, \& Schulenberg, 2011). These cases and Frankl's own life story demonstrate that death can be more than just its negative version, it can be used as a positive drive as well.

Influenced by this theory and other existential views, Wong, Reker and Gesser explored the positive dimension of death and developed Death Attitude Profile assessment tool, which was later revised to DAP-R (1994). Their careful conceptual and empirical analysis gave them 5 main attitudes towards death; Fear of Death, Death Avoidance, Neutral Acceptance, Approach Acceptance and Escape Acceptance. Fear of Death is the conventional negative thoughts and feelings about death. Death avoidance subscale was established after empirical studies showed that although this is a negative attitude, but in this condition people avoid thinking and talking about death altogether, which can be a form of defense mechanism. The other three attitudes differ from the previous negative ones. Neutral acceptance is indifference towards death, while approach acceptance sees death as a path to a better existence and believe in afterlife is integral for it. Escape acceptance though takes a negative view of life itself, and sees death as an escape from hardships.

The second important domain of this study besides death attitudes is meaning in life. Michael F. Steger (n.d.) who has done considerable work in this domain regards Meaning in Life as, "feeling that people have that their lives and experience make sense and matter". Frankl (1992) identified four important functions of Meaning in life for an individual. First, it provides purpose for our life. Second, it provides values and standards to judge our self. Third, provides a sense of control over our own life. Last, provides self-worth that is we are good and worthy individuals. The scale used here of Meaning in Life was developed by Steger, Frazier, Oishi and Kaler (2006). The authors of the scale distributed meaning in life in two clear sub-scales; search for meaning and presence of meaning. Presence of meaning doesn't imply absence of search, there are individuals who found meaning in life but kept up the active pursuit to find more. Researchers have shown that both scales are greatly independent with some support for convergence. Although, increase in search where results in negative affect, also increases inquiry and deeper involvement in life. (Steger, Kashdan, Sullivan \& Lorentz, 2008).

Building upon these concepts, when death attitudes and meaning in life are taken together, existential approach backs them up. Existential/ humanistic psychology asserts that self-actualization is only possible when a person comes to accept his/her personal death. Victor Frankl, as mentioned before, believed finding meaning in one's life removes fear of death and increases one's well-being. Wong's existential-spiritual model of aging proclaims, positive meanings of life and death provide the necessary motivation for pursuing a healthy life style as well as worthy life goals. Following this a person can live a highly-satisfied life even when faced with physical ailments (Wong, Reker and Gesser, 1994). These theories emphasize that a link exists between meaning in life and death attitudes. Thus, these constructs are worth examining together.

Drawing from these theories and literature Death Attitude was paired with the construct of Meaning in Life. This remains a fertile ground to research upon, exploring how search for meaning and presence of meaning in life links with the death attitudes. Greater number of researches exist regarding negative death attitude. While, those on positive death attitudes are mostly concerned with aging and end of life care. This study was exclusively conducted on youth population. To see how research in this domain can be used for the wider benefit of the society. How working on death can help us increase meaning in life of the masses. Thus, an effort to reconcile existential approach and positive psychology.

Apart from exploring the relationship between meaning in life and death attitude. A secondary purpose was to see whether youth population has significantly higher search for meaning as compared to presence of meaning in life. Gender was also taken as an important variable to explore upon. Insights regarding this matter would help in developing interventions for future in the domain of positive psychology to help individuals live a fuller purposeful life.

\section{METHODOLOGY}

\subsection{Sample}

By the method of convenient sampling 120 students were recruited for the study from University of Karachi, $50 \%$ male participants and $50 \%$ female participants. Participants were from variety of departments and faculties, ensuring heterogeneity in the sample.

\subsection{Measures}

\subsubsection{Death Attitude Profile-Revised (DAPR)}

As mentioned before DAP-R was developed by Wang, Reker \& Geser in 1994. It consists of 32 questions in a sevendegree Likert scale (from strongly agree $=7$ to strongly disagree $=1$ ). Cronbach's Alpha coefficients of this questionnaire are as follows: Fear of Death $(F D)=0.86$; Death Avoidance $(D A)=0.88$; Neutral Acceptance $(N A)=0.65$; Approach Acceptance $(A A)=0.97$; Escape Acceptance $(E A)=0.84$. Validity evaluation of the test has been reported by differential and convergent validity to other tests (Lobb, 2009). DAP-R is conceptually more sound and internally consistent as compared to its earlier version, DAP. Made after careful analysis of different assessment tools and theories. Test-retest showed 
Alpha coefficients and stability coefficients range from good to very good. Construct validity was also confirmed by the research (Wong, Reker and Gesser, 1994). The items corresponding to its five dimensions are; Fear of Death (1, 2, 7, 18, 20, 21, 32), Death Avoidance (3, 10, 12, 19, 26), Neutral Acceptance (6, 14, 17, 24, 30), Approach Acceptance (4, 8, 13, 15, 16, 22, 25, 27, 28, 31) and Escape Acceptance (5, 9, 11, 23, 29).

\subsubsection{Meaning In Life Questionnaire (MLQ)}

The 10 item MLQ was developed by Steger, Frazier, Oishi and Kaler in 2006. Meaning in life is assessed on 7 point Likert scale $(1=$ Absolutely Untrue to $7=$ Absolutely True). The MLQ measures meaning in life on two dimensions, the Search for Meaning and Presence of Meaning. The Search for Meaning subscale measure how motivated individuals are to finding meaning in their lives and to increase their understanding of meaning (Items 2, 3, 7, $8 \& 10$ ). The Presence of Meaning subscale measures how full of meaning individuals consider their life to be (Items 1, 4, 5, 6 \& 9*reverse scored). Several studies have shown that MLQ has good internal consistency and test-retest reliability. Studies have also established good convergent and divergent validity (Steger et al., 2006).

\subsection{Procedure}

To obtain the required data, students were approached in the university. After taking their verbal consent to participate, they were given the questionnaires, demographic sheet and the written consent. Since the topic of death remains sensitive for masses, the research topic was clearly mentioned in the written consent form, giving participants wide berth to withdraw if the case be. Two participants withdrew after reading the topic while few students were attracted by the research topic and volunteered to participate in the study. Death questionnaire had some difficult English words therefore in foresight a list of meaning of difficult word was prepared from the oxford dictionary. Only synonyms and meaning of difficult words were listed, phrases were not translated. Clarification to participants was provided with the help of this list. To ensure diversity in the sample, students from various faculties and departments were approached.

After all the data was collected, and scoring was completed, tabulated result was subjected to statistical analysis with the help of SPSS software.

\section{Result}

The mean age of 60 male participants was 21.5 years, while the mean age of 60 female participants was 21.2 years Students primarily were from four major faculties of University of Karachi; Social Sciences (27.5\%), Pharmacy (25.8\%), Science (25.0\%), and Management and Administrative Sciences (21.7\%) showing heterogeneity in the sample.

First it was evaluated whether gender had any role and does it impact death attitude and meaning in life scores. Only two significant relationships emerged. That is the scores of males and females significantly differed for the variables; fear of death and neutral acceptance. On both occasion, females scored significantly higher than males, that is female participants had greater fear of death as well as greater neutral acceptance (Table 1).

Table 1: Gender difference

\begin{tabular}{|c|c|c|c|c|}
\hline & Male & Female & T-value & Significant at \\
\hline Fear of Death & 30.83 & 34.37 & -2.500 & 0.014 \\
\hline Neutral Acceptance & 27.80 & 30.15 & -3.355 & 0.001 \\
\hline
\end{tabular}

After examining gender differences, paired sample t-test was applied to see whether on average search for meaning in life is significantly greater as compared to presence of meaning in life in university's youth population. Result is tabulated below.

Table 2: Paired Sample T-test for search and presence (meaning in life)

\begin{tabular}{|c|c|c|c|c|}
\hline Search & Presence & Mean Difference & T-value & Significant at \\
\hline 26.83 & 24.38 & +2.44 & +3.06 & 0.0013 \\
\hline
\end{tabular}

As Table 2 shows, university population scored significantly higher on search sub-scale and it was significant at alpha = 0.01 . To explore the relationship between death attitudes and meaning in life, Pearson correlation was applied. As Table 3 shows, search for meaning was significantly and positively associated with two death attitudes; fear of death and escape acceptance. While, presence of meaning was significantly negatively linked with fear of death and positively linked with neutral acceptance. The other two death attitudes; death avoidance and approach acceptance of death weren't significantly associated with either of the subscales of meaning in life. 
Table 3: Relationship between death attitudes and meaning in life

\begin{tabular}{|r|r|r|r|}
\hline & Fear of Death & Neutral Acceptance & Escape Acceptance \\
\hline Search for Meaning & Sign $=0.002$ & Not Significant & +0.229 \\
& Sign $=0.012$ \\
\hline Presence of Meaning & Sign $=0.002$ & +0.278 & Not Significant \\
\hline
\end{tabular}

Correlation analysis between death attitudes subscales was also conducted (see Table 4). Results show that fear of death is positively and significantly associated with death avoidance and escape acceptance. Death avoidance was positively associated with escape acceptance. Approach acceptance was also positively correlated with escape acceptance. While, neutral acceptance of death wasn't correlated with any of the death attitudes.

Table 4: Correlation between death attitudes.

\begin{tabular}{|c|c|c|c|c|c|}
\hline Death Attitudes & FD & DA & NA & AA & EA \\
\hline FD & $x$ & $\begin{array}{c}+0.313 \\
\text { Sign }=0.001\end{array}$ & Not Sign & Not Sign & $\begin{array}{c}+0.335 \\
\text { Sign }=0.000\end{array}$ \\
\hline DA & $\begin{array}{c}+0.313 \\
\text { Sign }=0.001\end{array}$ & $x$ & Not Sign & Not Sign & $\begin{array}{c}+0.199 \\
\text { Sign=0.029 }\end{array}$ \\
\hline NA & Not Sign & Not Sign & $x$ & Not Sign & Not Sign \\
\hline AA & Not Sign & Not Sign & Not Sign & $x$ & $\begin{array}{c}+0.374 \\
\text { Sign at }=0.000\end{array}$ \\
\hline EA & $\begin{array}{c}+0.335 \\
\text { Sign }=0.000\end{array}$ & $\begin{array}{c}+0.199 \\
\text { Sign=0.029 }\end{array}$ & Not Sign & $\begin{array}{c}+0.374 \\
\text { Sign at }=0.000\end{array}$ & $x$ \\
\hline
\end{tabular}

\section{DISCUSSION}

The study conducted proved to be a success, giving various insights that could be worked upon in future. First, gender analysis comes into the focus. Female youth population had greater fear of death and neutral acceptance as compared to their male counterparts. On other constructs, variability between both genders was not significant. From early on, studies conducted to research upon death anxiety and fear has given congruent results. Research using Templer Death Anxiety Scale showed, females have significantly higher level of death anxiety (Chuin \& Choo, 2009). Other studies also support this result, where females in youth population report significantly higher death anxiety (John et al., 2007) and in dying patients' population females initiate death talk on greater level as compared to males (Skulason et al., 2014). Early studies conducted by the author of DAP-R revealed that females were more accepting of death (although it was on the dimension of AA and EA) (Wong, Reker, Gesser, 1994).

Why this is so can be explained by various reasons. John and colleagues (2007) in their study showed that besides death anxiety, women also score higher on extrinsic religiosity scale. They contemplated that gender differences in death anxiety could partially be explained by gender differences in extrinsic religiosity and unveiled two alternative theoretical models of causal links: (a) women's higher death anxiety promotes extrinsic religiosity or (b) women's higher extrinsic religiosity promotes greater death anxiety. These models though need further research, but extrinsic religiosity is certainly linked with death anxiety. This could also be a reason for higher death acceptance for females which in reality might be existing on surface level only. Another idea can be derived from Skulason and colleagues (2014), who researched on death talk. Dying women patients initiated greater death talk, this might demonstrate acceptance of death on surface level by showing willingness to speak, while maintaining the related death anxiety beneath. Women in our culture are also encouraged more to speak of their feelings compared to males. The way of expression might be contributing negatively to death attitude. Further research in this domain can help identify the features of death fear in females and whether this fear is for self or others. Also, it needs to be identified whether this neutral acceptance is the actual belief held or is on surface level only. 
Our hypothesis, 'search for meaning in life will be significantly greater to presence of meaning in life in youth population' was proved. One research on similar issue took participants from 18 years to 65 years and older age. The research results revealed that those at earlier stages of life report higher levels of search for meaning (Steger, Oishi, \& Kashdan, 2009). Another research by Reker, Peacock \& Wong (1987) showed that Life Purpose increases with age while Goal Seeking decreases. These studies support our result, but what's different in our study is that scores of search for meaning of each participant was compared with presence of meaning. And generally, in youth population it was seen search remains higher as compared to presence. Erikson's psychosocial stages give insight regarding this matter. The fifth stage of identity vs role confusion and sixth stage intimacy vs isolation are the key here (McLeod, 2013). In both stages, people are in exploration phase. Although Erikson gave the fifth stage for 12-18 years, but search for one's identity usually extends to adulthood today. People are constantly trying to find their place in the world. Much uncertainty and identity crisis exists and can be very unsettling for the young. Such uncomfortable phase thus is marked by increased search for meaning to develop one's identity and find one's rightful place in the world.

An important component of the study was to explore the relationship between meaning in life and death attitudes. It was seen that search for meaning was significantly and positively associated with fear of death and escape acceptance. While, presence of meaning was significantly negatively linked with fear of death and was positively related to neutral acceptance. From this we can infer both constructs are intertwined. Study on purpose and meaning by Durlak (1972) showed greater purpose in life was marked by less fear of death and more positive attitude and acceptance of death. Another study by Quinn \& Reznikoff (1985) found that lack of purpose and direction was marred by higher levels of death anxiety. These results are consistent with the result obtained in this study. Search for meaning though has mixed findings in the literature. In Powell's thesis (2010), search for meaning was negatively correlated with Death Avoidance. Here in our study though relation between search and fear of death \& escape acceptance was seen. Drawing from previous theories of existential domain and Erikson's psychosocial stages, one can infer that early life is marked by search and uncertainty. Since the person has yet to find meaning in life and is searching for place in this world, they haven't fulfilled their life's purpose. Without the fulfillment of life's purpose, death fear remains high as was also seen in Victor Frankl's theory. And as existential theory marks self-actualization as coming in terms with one's mortality we see that self-actualized individuals have found purpose and derive great satisfaction from life. Another relation of escape acceptance and search for meaning can be subjected to great discomfort and dissonance search for meaning causes. This discomfort can give rise to escape acceptance attitude towards death.

The study also found relationship between subscales death attitudes for secondary purpose. Fear of death was positively and significantly associated with death avoidance and escape acceptance. Fear of death and death avoidance where take negative view of death, escape acceptance takes negative view of life. This might have resulted in significant correlation. Also, death avoidance was positively associated with escape acceptance. Approach acceptance was positively correlated with escape acceptance. Both subscales take positive view of death which might have resulted in this relationship. While, neutral acceptance of death wasn't correlated with any of the death attitudes. Showing that neutral attitude asserts an indifferent attitude and no relation also signifies strength of the DAP-R instrument.

\section{LIMITATIONS}

One limitation mentioned in the procedure section as well pertains to the word difficulty in DAP-R. As a precautionary measure, a list of meanings was developed but this limitation needs to be mentioned. Also, the results obtained cannot be generalized overall, and context needs to be considered. As this study was conducted in Pakistani university with majority of Muslims as participants. When applying findings, this context needs to be kept in mind

\section{CONCLUSION}

A major purpose of conducting this study was to open possibilities in death research. Major chunk of literature has been dedicated to negative death attitudes and even positive ones are mostly associated with end of life care perspective. Its high time to integrate existential philosophy and positive psychology. As Wong (2007), has mentioned many times in his research and articles, to quote, "a mature positive psychology cannot be exclusively based on positive experiences and positive affects". Deriving meaning from the death and suffering is integral to growth. Meaning in life and death attitudes are considerably linked as this study showed. Therefore, future researches should now focus on intervention studies and death education. Movies can be used as a great media to propagate this information as well. Variety of negative attitudes observed in calamity situations can also be accounted for and a proactive approach can be taken. In the end, Eissler (1955) famous quote will be cited here to reiterate the importance of this topic; "We are mistaken to consider death as a purely biological event. The attitudes concerning it, and its meaning for the individual, can serve as an important organizing principle in determining how he conducts himself in life."

\section{REFERENCES}

1. Chuin, C. L., \& Choo, Y. C. 2009. Age, gender, and religiosity as related to death anxiety. Sunway Academic http://eprints.sunway.edu.my/62/1/AGE, GENDER, AND RELIGIOSITY AS RELATED TO DEATH.pdf

2. Durlak, J. A. 1972. Relationship between individual attitudes toward life and death. Journal of Consulting and Clinical Psychology, 38, 463.

3. Eissler, K. R. 1955. The Psychiatrist and the dying patient. New York: International Universities Press. 
4. Fiefel, H. 2016. Encyclopedia of death and dying. Retrieved from http://www.deathreference.com/En-Gh/FeifelHerman.html

5. Frankl, V. 1992. Man's Search for Meaning. (4th ed.). Boston, MA: Beacon Press.

6. Frankl, V. E. 1985. Man's search for meaning (Revised and updated ed.). New York, NY: Washington Square Press.

7. John, P., Cohen, A., Chambers, J. A., \& Meade, R. M. 2007. Gender differences in death anxiety and religious orientation among US high school and college students. Mental Health Religion and Culture, 10 (2), 143-150. Retrieved https://www.researchgate.net/publication/249000554 Gender differences in death anxiety and religious orien tation among US high school and college students

8. Langer, T. S. 2002. Choices for living: coping with fear of dying. New York: Dordrecht.

9. Lobb, B. N. 2009. Age, intrinsic religiosity, meaning in life and attitude toward death. Scholars: Journal of undergraduate research, 12. Retrieved from https://www.mckendree.edu/academics/scholars/issue12/lobb.htm

10. McLeod, S. A. 2013. Erik Erikson. Retrieved from www.simplypsychology.org/Erik-Erikson.html

11. Neimeyer, R. A., Wittkowski, J., \& Moser, R. P. 2004. Psychological research on death attitudes: An overview and evaluation. Death Studies, 28 (4), 309-40. DOI: 10.1080/07481180490432324

12. Niemiec, R. M., \& Schulenberg, S. E. 2011. Understanding death attitudes: The integration of movies, positive psychology, and meaning management. Death Studies, 35 (5), 387-407. Retrieved from https://www.ncbi.nlm.nih.gov/pubmed/24501852

13. Nozari, M., \& Dousti, Y. 2013. Attitude toward death in healthy people and patients with diabetes and cancer. Iran Journal of Cancer Prevention, 6, 95-100. PMCID: PMC4142918.

14. Powell, K. 2010. The relation of search for and presence of meaning in life to attitudes about death (Master thesis). Retrieved from http://scholarworks.calstate.edu/bitstream/handle/2148/614/Final Thesis.pdf?sequence=1

15. Quinn, P. K., \& Reznikoff, M. 1985. The relationship between death anxiety and the subjective experience of time in the elderly. International Journal of Aging Human Development, 21 (3), 197-210. Retrieved from https://www.ncbi.nlm.nih.gov/pubmed/3830904

16. Reker, G. T., Peacock, E. J., \& Wong, P. T. P. 1987. Meaning and purpose in life and well-being: A lifespan perspective. Journal of Gerontology, 42 (1), 44-49. Retrieved from http://www.drpaulwong.com/wpcontent/uploads/2013/09/1987-Reker-Peacock-Wong-Meaning-across-the-life-span.pdf

17. Skulason, B., Hauksdottir, A., Ahcic, K., \& Helgason, A. R. 2014. Death talk: gender differences in talking about one's own impending death. BMC Palliative Care, 13 (1), 8. Retrieved from https://www.ncbi.nlm.nih.gov/pmc/articles/PMC3975272/

18. Steger, M. F. Meaningful Living. Retrieved from http://www.michaelfsteger.com/?page id=113

19. Steger, M. F., Frazier, P., Oishi, S., \& Kaler, M. 2006. The Meaning in Life Questionnaire: Assessing the presence of and search for meaning in life. Journal of Counseling Psychology, 53, 80-93.

20. Steger, M. F., Kashdan, T. B., Sullivan, B. A., \& Lorentz, D. 2008. Understanding the Search for Meaning in Life: Personality, Cognitive Style, and the Dynamic Between Seeking and Experiencing Meaning. Journal of Personality, 76 (2), 199-228.

21. Steger, M. F., Oishi, S., \& Kashdan, T. B. 2009. Meaning in life across the life span: Levels and correlates of meaning in life from emerging adulthood to older adulthood. The Journal of Positive Psychology, 4 (1), 43-52. Retrieved from https://sccn612final.wikispaces.com/file/view/Meaning+in+Life+across+the+Life+Span.pdf

22. Wong, P. T. P. 2014. Viktor Frankl's meaning seeking model and positive psychology. In A. Batthyany \& P. Russo-Netzer (Eds.), Meaning in existential and positive psychology (pp. 149-184). New York, NY: Springer. Retrieved from http://www.drpaulwong.com/viktor-frankls-meaning-seeking-model-and-positive-psychology/

23. Wong, P. T. P. 2007. Viktor Frankl: Prophet of hope for the 21st century. In A. Batthyany \& J. Levinson (Eds.), Anthology of Viktor Frankl's Logotherapy. Phoenix, AZ: Zeig, Tucker \& Theisen Inc

24. Wong, P. T. P., Reker, G. T., \& Gesser, G. 1994. Death Attitude Profile-Revised: A multidimensional measure of attitudes toward death. In R. A. Neimeyer (Ed.), Death anxiety handbook: Research, instrumentation, and application. (pp. 121-148). Washington, DC: Taylor \& Francis.

25. Zusak, M. 2005. The book thief. Goodreads. Retrieved from http://www.goodreads.com/quotes/484106-here-is-asmall-fact-you-are-going-to 


\section{Authors' biography with Photo}

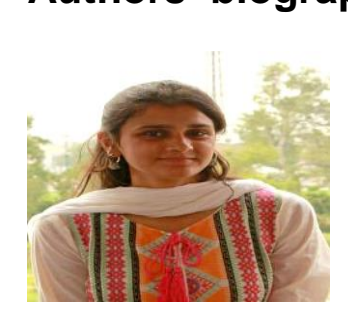

\section{Sarwat Amin Rattani}

A recent gradute of M.A Psychology from University of Karachi. Sarwat is greatly tilted towards Industial-Organizational Psychology \& Positive Psychology and aims to pursue postgraduate studies in the earlier discipline. A research enthusiastic, she interned previously at National Bank of Pakistan and Karwan-e-Hayat hospital. Sarwat conducted this research under the supervision of Dr. Farah lqbal.

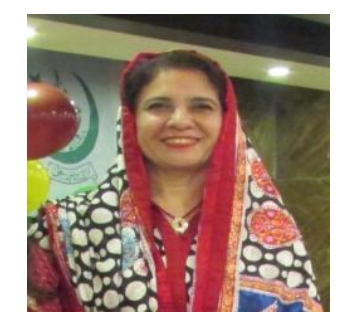

\section{Dr. Farah Iqbal}

Professor Dr. Farah is currently Chairperson of Department of Psychology, University of Karachi. Always seeking research projects in Human Psychology and Social Development Issues. She has vast teaching experience and has worked on numerous research projects. Some research work include UNICEF projects. She has also worked with different organziations in the capacity of Organizational Psychologist. 